\title{
Excess Molar Volumes of Binary Mixtures of Cyclohexane and $\gamma$-Butyrolactone with Aromatic Hydrocarbons
}

\author{
Willam E. Acree, Jr., ${ }^{\dagger}$ Khelrollah Gholaml, Danny R. McHan, and J. Howard Rytting \\ Department of Pharmaceutical Chemistry, The University of Kansas, Lawrence, Kansas 66045
}

\begin{abstract}
Excess molar volumes of cyclohexane + benzene, cyclohexane + toluene, cyclohexane + p-xylene, $\gamma$-butyrolactone + benzene, $\gamma$-butyrolactone + toluene, and $\gamma$-butyrolactone $+m$-xylene have been measured at 298.15 K. For the first three systems, $V^{E}$ ls positive throughout the entire concentration range. $V^{E}$ Is negative for blnary mixtures contalning $\gamma$-butyrolactone, which Indicates significant Interactlon between $\gamma$-butyrolactone and the aromatic hydrocarbon.
\end{abstract}

\section{Introduction}

In the chemical industry there exists a continuing need for reliable thermodynamic data of binary systems. This is particularly true for systems involved in industrial processes. A survey of the literature reveals that $\gamma$-butyrolactone is used in separation processes, yet there have been relatively few measurements on binary mixtures containing $\gamma$-butyrolactone. For this reason, we have determined the excess molar volumes $\left(V^{E}\right)$ of $\gamma$-butyrolactone + benzene, $\gamma$-butyrolactone + toluene, $\gamma$-butyrolactone $+m$-xylene, cyclohexane + benzene, cyclohexane + toluene, and cyclohexane $+p$-xylene at $298.15 \mathrm{~K}$.

\section{Experimental Section}

Benzene (Aldrich Gold Label), toluene (Aldrich Gold Label), $p$-xylene (Aldrich Gold Label), $\gamma$-butyrolactone (Aldrich Gold Label), $m$-xylene (MCB Spectroquality), and cyclohexane (Phillips $99.5 \%$ ) were stored over molecular sieves to remove trace amounts of water. Binary mixtures were prepared by weight so that concentrations could be calculated to 0.0001 mole fraction.

Densitles were measured with a SODEV Model 01D densimeter thermostated with a SODEV closed-loop temperature controller. The reproducibility of the programmable circulating thermostat was better than $0.005 \mathrm{~K}$ while the fluctuations in the temperature control unit were within $0.0003 \mathrm{~K}$ during the time required for each series of measurements. Samples were introduced into the vibrating densimeter tube by means of a multiport valve (Reodyne, Model 5011, six-position Teflon rotary valve). Using this sampling valve, we were able to determine densities in rapid succession. Flow rates of solutions were maintained constant at about $0.6 \mathrm{~mL} / \mathrm{min}$ to minimize errors due to flow rate variations. A pure liquid was run between each binary mixture, and the measured oscillation period for the pure liquid was used in density calculations for the preceding binary mixture. This procedure was found to correct for slow drifts in the vibrating-tube frequency and improve the reproduclbility $( \pm 2 \mathrm{ppm})$ of the density measurements. Picker et al. (1) describe the mechanical design and precision of vibrating-tube densimeters, as well as the calculational methods, in greater detail.

\section{Results}

The experimental results are listed in Table I, along with smoothing equations and standard deviations $\sigma\left(V^{E}\right)$. Excess

${ }^{\dagger}$ Current address: Department of Chemistry, Kent State University, Kent, $\mathrm{OH}$ 44242.
Table I. Molar Excess Volumes, Smoothing Equations, and Standard Deviations $\sigma\left(V^{\mathbf{E}}\right)$

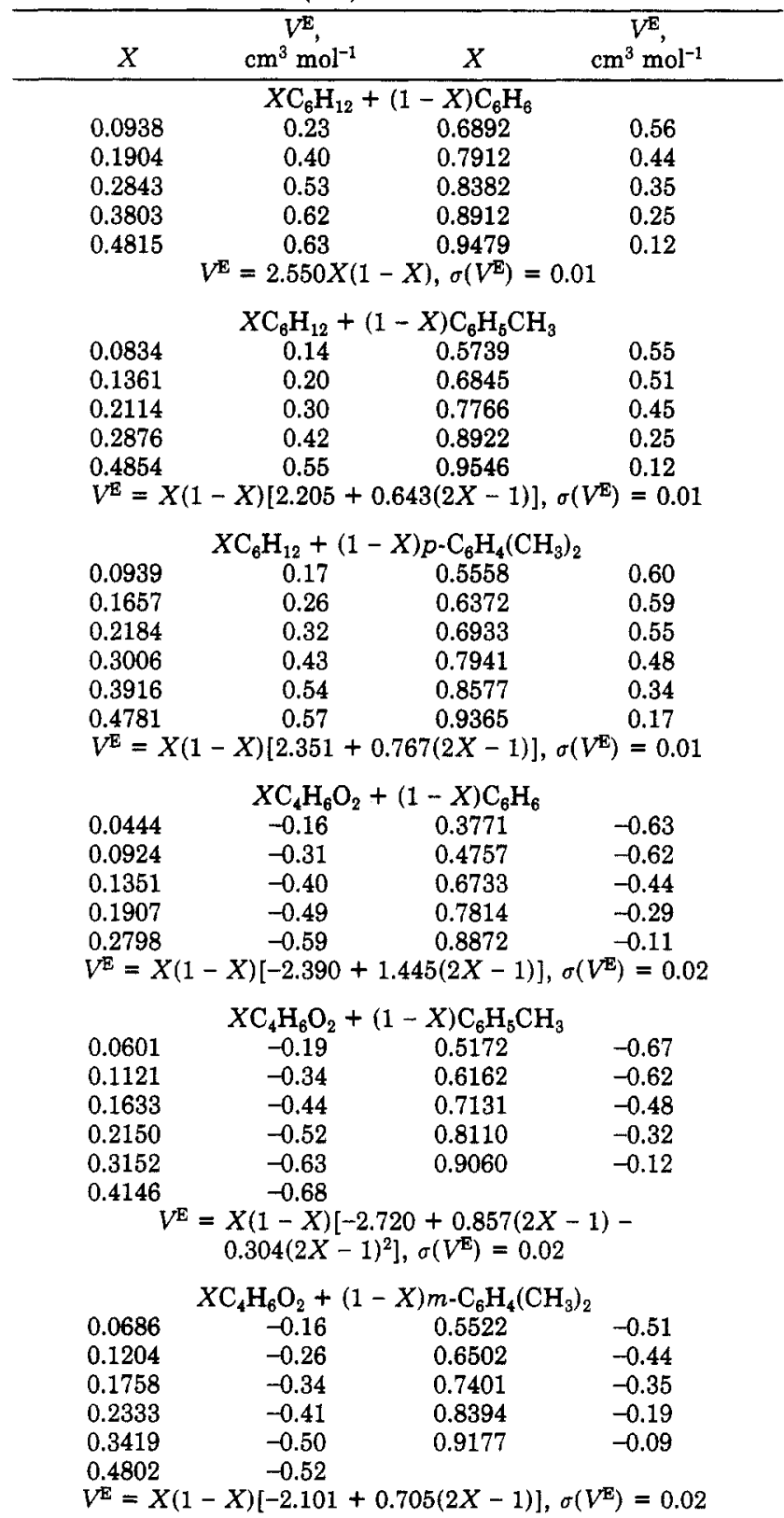

molar volumes of binary mixtures do provide valuable insight into molecular interactions. The negative excess volumes for the three systems containing $\gamma$-butyrolactone indicate complexation between $\gamma$-butyrolactone and the aromatic hydrocarbons. Attempts to estimate the association constant from the experimental data by using the ideal associated solution model were unsuccessful as the $V^{E}$ 's are not symmetrical with respect to mole fraction. Possible explanations for this unsymmetrical behavior are (1) formation of higher-order complexes, (2) physical interactions not being negligible compared to the chemical interactions, and (3) specific interactions between adjacent $\gamma$-butyrolactone molecules. On the basis of the 
limited number of experimental measurements it is impossible for us to conclude which of these explanations is most probable. Recent vapor pressure measurements by Grant et al. (2) on $\gamma$-butyrolactone + iscoctane mixtures do suggest very weak specific interactions between $\gamma$-butyrolactone molecules. Although the vapor pressure data could be described by a monomer/pentamer association model, the authors cautioned that their results did not definitively prove the existence of pentameric specles in solution. As in all cases, the presence of molecular complexes should be supported by independent measurements involving spectroscopy, calorimetry, etc.
Regletry No. Cyclohexane, 110-82-7; benzene, 71-43-2; toluene, 108-88-3; $p$-xylene, 106-42-3; $m$-xylene, 108-38-3; $\gamma$-butyrolactone, 9648-0.

\section{Llterature Clted}

(1) Picker, P.; Tremblay, E., Jolicoeur, C. J. Solution Chem. 1974, 3 , 377-84.

(2) Grant, D. J. W.; Higuchl, T.; Hwang, Y. T.; Rytting, J. H. J. Solution Chem. 1984, 13, 297-311.

Received for revlew March 15, 1984. Revised manuscript recelved August 9 , 1984. Accepted August 24, 1984.

\title{
Solubility of Hydrogen in Well-Defined Coal Liquids
}

\author{
Roland H. Harrison, ${ }^{*}$ Stuart E. Scheppele, ${ }^{\dagger}$ Gene P. Sturm, Jr., and Patrlck L. Grizzle ${ }^{\ddagger}$ \\ Bartlesville Energy Technology Center, ${ }^{\S}$ Department of Energy, Bartlesville, Oklahoma 74005
}

\begin{abstract}
The solubillty of hydrogen in Tetralln and several coal liquids was measured at high temperatures and pressures. A four-component synthetlc recycle solvent containing $43 \%$ Tetralin, $38 \%$ 2-methylnaphthalene, $17 \% p$-cresol, and $2 \%$ 4-plcolline was studled in a 2-L, stirred autoclave at temperatures of $125,200,275,350$, and $400{ }^{\circ} \mathrm{C}$ and at presesures of $5,10,15,20$, and $25 \mathrm{MPa}$. The solubllity of hydrogen in middle and heavy distillates from the Solvent Refined Coal II process (SRC II) was measured at the same temperatures and pressures. Denstties of the llquid phases were measured at operating conditions. Analyses of small, thermally induced, changes in the compositions of the mixtures are presented. The occurrence of a hydrogen disproportionation reaction is Indicated for the four-component mixture. There appeared to be a greater conversion of aromatic hydrocarbons to saturated hydrocarbons than heteroatom compounds to hydrocarbons and other products in the middle and heavy distlliate mixtures. Additional propertles of SRC II llqulds, such as results of Bureau of Mines routine method dlstillation, viscosity, specific gravity, detalled elemental and chemical-type analyses, and enthalples of combustion, are presented as suppiementary material.
\end{abstract}

\section{Introduction}

The liquefaction of coal to produce fuels and possibly chemical feedstocks requires much research in chemlcal and phase equilibrium for suitable design, product distribution, and energy utilization. Thus, the Bartlesville Energy Technology Center of the U.S. Department of Energy conducted a research program in support of the program for development of the Solvent Refined Coal II process. The coal liquids studied in this project were produced during run 77SR-12 (1) at the Fort Lewis pilot plant which charged Pittsburgh seam coal from the Blacksville (WV) Mine No. 2. That run produced yields (weight percent moisture-ash-free coal) of $5.9 \%$ naphtha, $17.9 \%$ middle distillate, and $5.8 \%$ heavy distillate. Samples from that run were labeled 1007, 1008, and 1009, respectively. The solubility of

\footnotetext{
'Present address: Bartlesville Project Office, Department of Energy, Bartles-

ville, OK 74005.

Present address: Sun Exploration, Richardson, TX 75080.
Now the National Institute for Petroleum and Energy Research, Bartlesville, OK 74005 .
}

hydrogen in samples 1008 and 1009 is reported in this report along with the densities of the phases at equilibrium. Physical and chemical properties for all three samples have been reported by Brinkman and Bowden (2).

The naphtha, middle distlllate, and heavy distillate fractions showed some overlap by simulated distillation chromatography. Thus, a blending was made in the ratio 5.9:17.9:5.8, and a more precise distillation using a 75-plate spinning-band still provided fractions of $200,200-325$, and $325-425^{\circ} \mathrm{C}$ distillates and a $425+{ }^{\circ} \mathrm{C}$ residuum. The distribution of the new fractions was $28.0 \%, 58.8 \%, 8.6 \%$, and $2.7 \%$ with a loss of $1.9 \%$. A standard crude petroleum analysis on the blended stock and analyses on the distillation fractions such as elemental and chemical type are given as supplementary material (see paragraph at end of text regarding supplementary materlal).

The project to measure the solubility of hydrogen in coal liquids was developed through the phases of design, construction, testing by measurements of hydrogen solubility in Tetralin, measurements of the solubillty of hydrogen in a four-component synthetic recycle solvent mixture, and measurements of hydrogen solubility in middle and heavy distillates from the SRC II process. The methods were extended to measure the composition of the vapor phase at equllibrium for the hydrogen-Tetralin system.

\section{Apparatus}

A static system with a 2-L autoclave was selected for this project because (1) it was simple to operate, (2) the cost was relatively low, (3) design, assembly, and operation were possible in shortest time, (4) it gives reasonable accuracy, and (5) it was deemed best suited for study of coal liquids and complex systems containing water, ammonia, and hydrogen sulfide as well as hydrogen. The static system suffers most from increased probability of sample reactions at high temperatures owing to the long exposure times. That problem will be discussed later in the paper.

The high-pressure equipment was located in a special-purpose laboratory for hydrogen solubility and coal hydrogenation projects. The autoclave and sampling system are shown in Figure 1. All parts of the autoclave and sampling system that contacted the fluids were made with type 316 stainless steel except the short tubing between the autoclave and valve 1, which was made from type 347 stainless steel. The studies were made with $1300 \mathrm{~cm}^{3}$ of liquid in the vessel at operating 